\title{
Response Surface Optimization of Flavonoids Extraction, Beta Carotene Bleaching and Lipid-reducing Capacity of Nelumbo nucifera Seed Kernel Extracts
}

\author{
Haq Nawaz ${ }^{1, *}$, Muhammad Aslam Shad ${ }^{1}$, Mohibullah Shah', Adnan Amjad ${ }^{2}$, Tanzila Rehman ${ }^{3}$, \\ Arif Mehmood ${ }^{4}$, Dure Shahwar ${ }^{1}$, Sabiha Tahir Abbasi ${ }^{4}$ \\ ${ }^{1}$ Department of Biochemistry, Bahauddin Zakariya University, Multan, PAKISTAN. \\ ${ }^{2}$ Institute of Food Science and Nutrition, Bahauddin Zakariya University, Multan, PAKISTAN. \\ ${ }^{3}$ Department of Chemistry, Women University, Multan, PAKISTAN. \\ ${ }^{4}$ Institute of Chemical Sciences, Bahauddin Zakariya University, Multan, PAKISTAN.
}

\begin{abstract}
Aim/Background: The safe and complete extraction of flavonoids from plant material influenced by various factors has been ever challenging for the researchers. The study was planned to optimize the extraction of flavonoids from nucifera seeds and their antioxidant activity. Materials and Methods: The flavonoids were extracted at various combination of four extraction factors including particle size of the flour in terms of sieve number (SN), microwave treatment time (MTT), concentration of methanol as extracting solvent $(\mathrm{CM})$ and soaking time (ST) each at five levels using a response surface central composite design. The extracts were analyzed for total flavonoid content (TFC), $\beta$-carotene bleaching capacity (BCBC) and linoleic acid reduction capacity (LARC). Results: A statistically significant $(p<0.05)$ effect of the extraction factors was observed on TFC, BCBC and LARC. A linear positive effect of MTT and CM and a quadratic positive effect of SN and CM was observed on TFC. The BCBC and LARC were also found to be increased linearly by increasing the SN, MTT and CM. The levels of SN, MTT, CM and ST to obtain optimal value of TFC $(1.468 \mathrm{~g} / 100 \mathrm{~g}$ dry weight) were found to be 132.94 meshes/inch, $1.85 \mathrm{~min}, 99.87 \%$ and $3.06 \mathrm{~h}$ respectively. Conclusion: The increase in TFC by increasing the MTT and CM may be attributed to the microwaveassisted release of bound flavonoids and their amphiphilic structure. The data would be a valuable guideline for the researchers regarding the extraction of plant flavonoids and their antioxidant potential.
\end{abstract}

Key words: Linoleic acid reduction capacity, Lotus seed kernel, Microwave-assisted extraction, Nelumbo nucifera seed, Response surface methodology, Total flavonoids content.

\section{INTRODUCTION}

The discovery of natural sources of phytochemical antioxidants and the development of suitable and effective methods of their extraction has been the attractive topic of research in the field of pharmacology and medicine. Plants are the major sources of bioactive phytochemical compounds which possess antioxidant potential. The complete and safe extraction of these compounds from their sources has been challenging for the researchers working on the nutritional, medicinal and pharmaceutical importance of various plant resources. Several factors have been reported to affect the extraction yield of these phytochemicals from plant materials. Particle size, processing conditions, the polarity of extracting solvent, extraction method and soaking time are some of these factors which may have significant effects on the extraction and biological activity of these compounds.
Submission Date: 06-06-2020; Revision Date: 02-12-2020; Accepted Date: 08-01-2021

DOI: 10.5530/ijper.55.1s.50 Correspondence: Dr. Haq Nawaz

Department of Biochemistry, Bahauddin Zakariya

University, Multan-60800, PAKISTAN.

Phone no: +92-061-9210391 Email id: haqnawaz@bzu. edu.pk

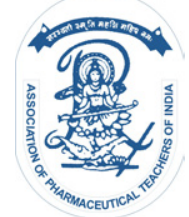

www.ijper.org 
The physical techniques including ultra-sonication, microwave and other thermal treatments have been proposed to increase the extraction yield of the bound phytochemicals from plant material even at relatively larger particle sizes. ${ }^{1-6}$ The microwave treatment has been proved to be effective in releasing the bound phytochemicals and increasing the extract yield. However, the prolonged microwave heating may result in thermal degradation of the phytochemicals. $2,5,7,8$

Flavonoids are a class of the antioxidant phytochemicals present in various parts of higher plants. Flavonoids possess strong antioxidant activity in terms of metal and lipid reducing, beta-carotene bleaching and free radical scavenging capacities and are also effective in protection against cardiovascular damage. ${ }^{9-11}$ These compounds usually have a molecular structure consisting of an aromatic, hydrocarbon skeleton with hydrophilic as well as hydrophobic substituents. The amphiphilic nature of flavonoids makes them unable to be extracted completely in either the polar or the nonpolar solvents. It is, therefore, necessary to find out a suitable solvent system with intermediate polarity to ensure the complete or desirable extraction of these compounds from plant material. $^{12-14}$

Nelumbo nucifera, locally known as lotus, is a rich source of nutritional components that possesses a good medicinal value due to the presence of nonnutritional phytochemical compounds particularly the flavonoids. The N. nucifera seeds are a rich source of bioactive flavonoids and show various biological activities including anti-hepatotoxic, anti-proliferative, anti-cancer, anti-inflammatory, anti-obesity and strong antioxidant activities. ${ }^{15-22}$ Previously, the studies have been performed on the extraction optimization and antioxidant activities of phytochemicals from various plant materials but limited data has been found regarding the influence of various extraction factors on the extraction of flavonoids from $N$. nucifera seed. In the present study, the cumulative effect of four factors including the particle size of the flour, microwave treatment time, the concentration of methanol as extracting solvent and soaking time on total flavonoid content and antioxidant activity of $N$. nucifera seed kernel was optimized by response surface methodology (RSM), a statistical tool used for the multivariate optimization.

\section{MATERIALS AND METHODS}

The seed kernels from $N$. nucifera seeds, purchased from the local market, were separated manually by removing the seed coat. The seed kernels were ground in an electric grinder and the temperature was maintained at $30 \pm 3^{\circ} \mathrm{C}$ to minimize the chances of thermal degradation of flavonoids. The seed kernel flour (SKF) thus obtained was sealed in airtight glass jars and stored in dark at sterilized laboratory conditions.

\section{Experimental Design}

The simultaneous effect of four extraction factors including the particle size of the flour taken inversely proportional to sieve number ( $\mathrm{SN})$, microwave treatment time (MTT), the concentration of methanol (CM) as extracting solvent and soaking time (ST) on total flavonoid content (TFC), $\beta$-carotene bleaching capacity (BCBC) and linoleic acid reduction capacity (LARC) of $N$. nucifera seed kernel was optimized by RSM using a 4-factorial five-level central composite design (CCD). A secondorder polynomial quadratic model was proposed to optimize the levels of extraction factors to achieve the optimal response. The five levels of SN, MTT, CM and ST were selected in the range of 60-140 meshes/inch, 0.5-2.5 min, $20-100 \%$ and $1-5 \mathrm{~h}$ with the interval of 20 meshes/inch, $0.5 \mathrm{~min}, 20 \%$ and $1 \mathrm{~h}$ respectively. A total of 30 experimental runs were proposed by the suggested model including 8 axial, 6 center and 16 factorial points (Table 1).

\section{Sieving}

The N. nucifera SKF was subjected to successive sieving through a series of micro sieves having mesh number 60 , 80, 100, 120 and 140 meshes/inch. A gradual increase in sieve number resulted in a proportional decrease in particle size (178-250, 150-177, 126-149, 106-125 and $<106 \mu \mathrm{m}$ respectively) and an increase in surface area (Sigma Aldrich 2014).

\section{Microwave treatment of flour}

The SKF (50 g) obtained from various sieves, was heated (sample mass of $10 \mathrm{~g}$ per load) in a microwave oven (LG: MS-1944WP, LG Electronics Inc.) at low power radiation intensity $(200 \mathrm{~W})$ and treatment time as suggested by CCD. The burning of the flour was prevented by discontinuing the treatment after each min and mixing of the flour.

\section{Preparation of extracts}

The native SKF $(1 \mathrm{~g})$ of particle size $<250 \mu \mathrm{m}$ (SN: 60 meshes/inch) was extracted in 80\% methanol (1:10 $\mathrm{w} / \mathrm{v})$ for $5 \mathrm{~h}$ while the microwave irradiated flour $(1 \mathrm{~g})$ at selected levels of SN and MTT was extracted at various combinations of CM and ST as per chosen by CCD. The volume of each of the crude methanolic extracts was made up to $10 \mathrm{ml}$ and used for the spectrophotometric determination of TFC, BCBC and LARC. 
Table 1: Experimental values of total flavonoid content (TFC), $\beta$-carotene bleaching capacity (BCBC) and linoleic acid reduction capacity (LARC) of $N$. nucifera seed flour extracted at various combinations of extraction factors as selected by the central composite design.

\begin{tabular}{|c|c|c|c|c|c|c|c|c|}
\hline Std. & Runs & $\begin{array}{c}\mathrm{X}_{1} \\
\text { Sieve number } \\
\text { (meshes/inch) }\end{array}$ & $\begin{array}{c}\mathrm{X}_{2} \\
\text { Microwave } \\
\text { treatment } \\
\text { time (min) }\end{array}$ & $\begin{array}{c}\mathrm{X}_{3} \\
\text { Conc. of } \\
\text { methanol. (\%) }\end{array}$ & $\begin{array}{c}X_{4} \\
\text { Soaking } \\
\text { time (h) }\end{array}$ & $\begin{array}{c}\text { TFC } \\
(\mathrm{g} / 100 \mathrm{~g} \mathrm{dw})\end{array}$ & ВСВС (\%) & LARC (\%) \\
\hline \multicolumn{2}{|c|}{ Native flour } & 60 & 0 & 80 & 5 & $0.23 \pm 0.06$ & 50.65 & 62.87 \\
\hline 28 & 1 & 100 & 1.5 & 60 & 3 & 0.35 & 49.31 & 58.35 \\
\hline 27 & 2 & 100 & 1.5 & 60 & 3 & 0.35 & 49.31 & 58.35 \\
\hline 16 & 3 & 120 & 2 & 80 & 4 & 0.58 & 77.09 & 51.01 \\
\hline 17 & 4 & 60 & 1.5 & 60 & 3 & 0.43 & 61.71 & 50.11 \\
\hline 9 & 5 & 80 & 1 & 40 & 4 & 0.21 & 57.1 & 55.28 \\
\hline 11 & 6 & 80 & 2 & 40 & 4 & 0.29 & 60.57 & 56.34 \\
\hline 15 & 7 & 80 & 2 & 80 & 4 & 1.07 & 70.31 & 60.13 \\
\hline 20 & 8 & 100 & 2.5 & 60 & 3 & 1.12 & 75.3 & 56.02 \\
\hline 6 & 9 & 120 & 1 & 80 & 2 & 1.23 & 69.6 & 67 \\
\hline 22 & 10 & 100 & 1.5 & 100 & 3 & 1.40 & 66.77 & 55.06 \\
\hline 8 & 11 & 120 & 2 & 80 & 2 & 0.66 & 74.97 & 47.01 \\
\hline 7 & 12 & 80 & 2 & 80 & 2 & 1.02 & 78.64 & 65.03 \\
\hline 29 & 13 & 100 & 1.5 & 60 & 3 & 0.35 & 49.31 & 58.35 \\
\hline 21 & 14 & 100 & 1.5 & 20 & 3 & 0.15 & 45.06 & 70.1 \\
\hline 26 & 15 & 100 & 1.5 & 60 & 3 & 0.35 & 49.31 & 58.35 \\
\hline 25 & 16 & 100 & 1.5 & 60 & 3 & 0.35 & 49.31 & 58.35 \\
\hline 12 & 17 & 120 & 2 & 40 & 4 & 0.52 & 45.61 & 49.25 \\
\hline 1 & 18 & 80 & 1 & 40 & 2 & 0.27 & 54.05 & 72.01 \\
\hline 10 & 19 & 120 & 1 & 40 & 4 & 0.28 & 60 & 77.03 \\
\hline 19 & 20 & 100 & 0.5 & 60 & 3 & 0.29 & 59.96 & 66.1 \\
\hline 18 & 21 & 140 & 1.5 & 60 & 3 & 0.96 & 64.16 & 60.02 \\
\hline 5 & 22 & 80 & 1 & 80 & 2 & 0.85 & 50.04 & 59 \\
\hline 13 & 23 & 80 & 1 & 80 & 4 & 0.93 & 55.89 & 66.04 \\
\hline 14 & 24 & 120 & 1 & 80 & 4 & 1.06 & 78.41 & 74.09 \\
\hline 24 & 25 & 100 & 1.5 & 60 & 5 & 0.35 & 61.26 & 65.03 \\
\hline 23 & 26 & 100 & 1.5 & 60 & 1 & 0.51 & 61.48 & 69.03 \\
\hline 2 & 27 & 120 & 1 & 40 & 2 & 0.17 & 57.95 & 76.07 \\
\hline 30 & 28 & 100 & 1.5 & 60 & 3 & 0.35 & 49.31 & 58.35 \\
\hline 4 & 29 & 120 & 2 & 40 & 2 & 0.25 & 59.95 & 56.34 \\
\hline 3 & 30 & 80 & 2 & 40 & 2 & 0.25 & 58.57 & 75 \\
\hline \multicolumn{6}{|c|}{ Mean \pm standard deviation } & $0.55 \pm 0.17$ & $60.01 \pm 3.19$ & $61.61 \pm 3.47$ \\
\hline \multicolumn{9}{|c|}{ Selected levels of extraction factors } \\
\hline \multicolumn{4}{|c|}{$\mathrm{X}_{1}$ : Sieve number (meshes/inch) } & 60 & 80 & 100 & 120 & 140 \\
\hline \multicolumn{4}{|c|}{$\mathrm{X}_{2}$ : Microwave treatment time $(\mathrm{min})$} & 0.5 & 1 & 1.5 & 2 & 2.5 \\
\hline \multicolumn{4}{|c|}{$\mathrm{X}_{3}$ : Conc. of methanol. (\%) } & 20 & 40 & 60 & 80 & 100 \\
\hline \multicolumn{4}{|c|}{$\mathrm{X}_{4}$ : Soaking time $(\mathrm{h})$} & 1 & 2 & 3 & 4 & 5 \\
\hline
\end{tabular}




\section{Total flavonoid content}

TFC of N. nucifera SKF extracts obtained at selected combinations of extraction factors was determined by the previously described method. ${ }^{23}$ The catechin equivalent TFC ( $\mathrm{g} / 100 \mathrm{~g} \mathrm{dw})$ was calculated using the regression equation (TFC $(\%)=$ Absorbance of the sample/0.898) obtained from the calibration curve of catechin $\left(R^{2}=0.986\right)$.

\section{$\beta$-Carotene bleaching capacity}

$\mathrm{BCBC}$ of extracts was determined by the previously described method. ${ }^{24}$ The BCBC was calculated as:

$$
\mathrm{BCB}(\%)=\left(\mathrm{ABS}_{120 \mathrm{~min}} / \mathrm{Abs}_{0}\right) \times 100
$$

Where $\mathrm{Abs}_{120 \min }$ is the absorbance of reaction mixture 120 min after addition of sample and $\mathrm{Abs}_{0}$ is the absorbance of the reaction mixture before the addition of the sample.

\section{Linoleic acid reduction capacity}

LARC of the extracts was determined by the method described earlier. ${ }^{25}$ The reaction mixture without sample was taken as control and the LARC was calculated as percent inhibition of lipid peroxidation in the linoleic acid system as:

$$
\operatorname{LARC}(\%)=\left[1-\left(\mathrm{Abs}_{\text {sample }} / \mathrm{Abs}_{\text {Control }}\right)\right] \times 100
$$

\section{Statistical analysis}

The TFC of the native flour was presented as the mean \pm standard deviation of three parallel replicates. The data on the TFC of extracts obtained from microwave treated flour at various combinations of extraction factors were statistically analyzed by a polynomial quadratic model using response surface CCD. The influence of extraction factors on TFC was determined by oneway analysis of variance (ANOVA), the significance of variation in data was measured in terms of the lake of fit (F-value) and probability ( $p$-value). The prediction of the optimum level of TFC, BCBC and LARC as a function of $\mathrm{SN}, \mathrm{MTT}, \mathrm{CM}$ and $\mathrm{ST}$ was done by the following generalized second-order polynomial regression equation:

$$
Y_{r}=\beta_{0}+\sum_{r=1}^{4} \beta_{r} X_{r}+\sum_{r=1}^{4} \beta_{r r} X_{r}^{2}+\sum \sum_{r<s=1}^{4} \beta_{r s} X_{r s}
$$

Where $Y_{\mathrm{r}}$ is the predicted value of a particular response, $\beta_{\mathrm{o}}, \beta_{\mathrm{r}}, \beta_{\mathrm{rs}}$ and $\beta_{\mathrm{rr}}$ are the regression coefficients for the main, linear, interaction and quadratic effect of input variables $X_{\mathrm{r}}$ and $X_{\mathrm{s}}$.
The linearity of the response, and the validity, precision and reliability of the proposed model were tested by determining the value of the coefficient of determination $\left(R^{2}\right)$, obtaining the predicted values of the responses and plotting against those obtained by experimental runs, and determining the adequate precision and coefficient of variation respectively. The optimum levels of extraction variables to achieve the maximal response were found by numerical optimization of the experimental data. The development of the response surface model, analysis of variance and optimization of variables were carried out in statistical software, Design Expert 10.0 (Stat-Ease, Inc.).

\section{RESULTS}

A multivariate effect of extraction factors including SN, MTT, CM and ST on TFC, BCBC and LARC of N. nucifera SKF extracts was optimized by RSM. The experimental results of TFC of the native $N$. nucifera SKF and that treated with microwave radiation and extracted at selected combinations of SN, MTT, CM and ST are presented in Table 1 . The TFC, BCBC and LARC of the native flour were found to be $0.23 \pm 0.06 \mathrm{~g} / 100 \mathrm{~g} \mathrm{dw}$ and 50.65 and $62.87 \%$ respectively. The TFC, BCBC and LARC of the microwave treated flour, extracted at selected levels of extraction factors, ranged from 0.15 to $1.4 \mathrm{~g} / 100 \mathrm{~g} \mathrm{dw}$ and 45.06 to 78.64 and 47.01 to $77.03 \%$ with mean \pm standard deviations of $0.55 \pm 0.17 \mathrm{~g} / 100 \mathrm{~g}$ $\mathrm{dw}$ and $60.01 \pm 3.19$ and $61.61 \pm 3.47 \%$ respectively. A statistically significant difference $(p<0.05)$ was observed in the TFC, BCBC and LARC of the extracts obtained at various combinations of extraction factors. The results for TFC were found to be comparatively lower than those reported in various extracts of $N$. nucifera seeds pod. ${ }^{15}$

\section{DISCUSSION}

The antioxidant potential and biological activity of any plant material mainly depend on its flavonoid composition. Some factors including the particle size of the material, extraction method, the nature of the extracting solvent, extraction temperature and soaking time may significantly affect the extraction yield of flavonoids from plant material which may further affect the evaluation of its biological activity. The plant material with relatively larger particle size gives low extract yield due to the limited interaction between the solvent molecules and the phytochemicals. Very small particle size ensures an increase in the surface area, intermolecular interaction and the extract yield. However, there are chances of degradation of phytochemicals during the fine grinding of plant material which may reduce the 
yield of the phytochemicals of interest. The increasing trends of microwave cooking of food and microwave assisted-extraction of phytochemicals in the research field have urged the researchers to investigate its advantages and drawbacks. Depending on the intensity of microwave radiation and duration of treatment, microwave-cooking and microwave-assisted extraction may significantly affect the extraction and biological activity of phytochemical compounds present in plant materials. The nature and concentration of the solvent and total soaking time may also affect the yield and quality of phytochemical compounds.

\section{Response surface analysis and optimization of results}

The experimental data were statistically analyzed using response surface models to find the levels of selected extraction variables in the optimal region of the TFC, BCBC and LARC of $N$. nucifera seeds extracts. The statistical terms showing the main, interaction and quadratic effects of SN, MTT, CM and ST on TFC, $\mathrm{BCBC}$ and LARC of extracts as obtained by one way analysis of variance (ANOVA) are presented in Table 2. The following polynomial regression equations were obtained to show the relationship between the extraction factors and the response:
The values of coefficient determination $\left(\mathrm{R}^{2}=0.8797\right.$ 0.9488 ) indicate that $87-94 \%$ variability of the TFC, BCBC and LARC could be explained by the proposed statistical model with high significance and good prediction. The relatively higher F-values and lower p-values obtained by one-way analysis of variance (ANOVA) of experimental data indicated a significant $(p<0.05)$ positive main effect of the selected input variable on each of the studied response. The statistically significant linear and quadratic positive effects of $\mathrm{CM}$ and quadratic positive effect of $\mathrm{SN}$ were observed on TFC. However, no significant interaction effect of the selected factors was observed on TFC. The linear, interaction and quadratic effects of $\mathrm{SN}$, MTT and $\mathrm{CM}$ were found to be significant on $\mathrm{BCBC}$. The linear effect of each of the selected factors, the interaction effect of SN, MTT and ST and quadratic effect of $\mathrm{CM}$ and ST were found to be significant on LARC. The calculated value of adjusted $R^{2}(0.7675-9011)$ also favors the significance of the proposed model. The values of coefficient of variation $(\mathrm{CV}=5.32-31.10 \%)$ and adequate precision ( $\mathrm{AP}=11.394-14.782)$ suggests a better precision of the experimental model claiming better reproducibility of the experiment at optimum levels of input variables as suggested by the model. The main, interaction and quadratic effects of SN, MTT, CM

$$
\begin{aligned}
& \begin{aligned}
\operatorname{TFC}(\mathrm{g} / 100 \mathrm{~g} \mathrm{dw}) & =0.666-0.027 X_{1}+0.52 X_{2}+6.420 \mathrm{E}^{-003} X_{3}-0.105 X_{3}-6.25 \mathrm{E}^{-003} X_{1} X_{2} \\
& -6.875 \mathrm{E}^{-005} X_{1} X_{3}-2.50 \mathrm{E}^{-004} X_{1} X_{4}-7.625 \mathrm{E}^{-003} X_{2} X_{3}+0.053 X_{2} X_{4} \\
& -1.188 \mathrm{E}^{-003} X_{3} X_{4}+2.135^{E-004} X_{1}^{2}+0.16 X_{2}^{2}+2.64 \mathrm{E}^{-004} X_{3}^{2}+0.019 X_{4}^{2}
\end{aligned} \\
& \begin{aligned}
\text { BCBC }(\%)= & 196.35-1.597 X_{1}-18.858 X_{2}-1.690 X_{3}-13.673 X_{4}-0.3709 X_{1} X_{2} \\
+ & 8.120 \mathrm{E}^{-003} X_{1} X_{3}-0.0123 X_{1} X_{4}+0.3217 X_{2} X_{3}-4.7888 X_{2} X_{4} \\
+ & 0.049 X_{3} X_{4}+8.968 \mathrm{E}^{-003} X_{1}^{2}+19.043 X_{2}^{2}+4.579^{-003} X_{3}^{2}+3.196 X_{4}^{2} \\
\text { LARC }(\%)= & 62.639+0.940 X_{1}+48.434 X_{2}-0.856 X_{3}-33.529 X_{4} \\
- & 0.592 X_{1} X_{2}-1.74219 \mathrm{E}^{-003} X_{1} X_{3}+0.119 X_{1} X_{4}+3.18750 \mathrm{E}^{-003} X_{2} X_{3} \\
- & 3.126 X_{2} X_{4}+0.171 X_{3} X_{4}-1.436 \mathrm{E}^{-003} X_{1}^{2}+3.697 X_{2}^{2}+3.260 \mathrm{E}^{-003} X_{3}^{2}+2.417 X_{4}^{2}
\end{aligned}
\end{aligned}
$$

and ST on TFC, BCBC and LARC of the extracts were also explained graphically by drawing their contour and three dimensional (3D) response surface plots (Figure 1 A-F, Figure 2A-F and Figure 3A-F). The predicted values of TFC, BCBC and LARC at each combination of input factors selected by experimental design were calculated from the polynomial regression equations and plotted against the experimental values of the respective responses to test the applicability of the suggested model (Figure 4A-C). A significant correlation was observed between the experimental and predicted values of responses with high values of correlation coefficients $\left(R^{2}=0.8813\right.$ 0.9489). The higher values of $R^{2}$ prove the applicability of the proposed model with good accuracy to study the effect of selected extraction factors on TFC, BCBC and LARC of N. nucifera seed kernel extracts.

The levels of the extraction factors to achieve the optimal value of TFC, BCBC and LARC with maximum desirability were numerically optimized within the selected range and maximum desirability (Figure 5 A-D). 
Table 2: Statistical parameters calculated from one-way analysis of variation (ANOVA) for optimization at various levels of selected variables.

\begin{tabular}{|c|c|c|c|c|c|c|c|c|c|c|c|c|}
\hline \multirow{2}{*}{ Source } & \multicolumn{4}{|c|}{ TFC (g/100 g dw) } & \multicolumn{4}{|c|}{ ВСВС (\%) } & \multicolumn{4}{|c|}{ LARC (\%) } \\
\hline & $\mathrm{CE}^{*}$ & SE & $F$-value & p-value & CE & SE & F-value & p-value & CE & SE & F-value & p-value \\
\hline Model & 0.35 & 0.070 & 7.84 & 0.0001 & 49.31 & 1 & 1.30 & $<0.0001$ & 58.35 & 1 & 1.42 & $<0.0001$ \\
\hline $\begin{array}{c}\text { A-SN } \\
\text { (meshes/ } \\
\text { inch). }\end{array}$ & 0.034 & 0.035 & 0.96 & 0.3420 & 1.80 & 1 & 0.65 & 0.0143 & 0.37 & 1 & 0.71 & 0.6124 \\
\hline$B-M T T$ (min) & 0.025 & 0.035 & 0.52 & 0.0483 & 3.06 & 1 & 0.65 & 0.0003 & -4.44 & 1 & 0.71 & $<0.0001$ \\
\hline C-CM (\%) & 0.32 & 0.035 & 86.25 & $<0.001$ & 6.02 & 1 & 0.65 & $<0.0001$ & -2.42 & 1 & 0.71 & 0.0038 \\
\hline$D-S T(h)$ & $\frac{-7.500 \mathrm{E}^{-}}{003}$ & 0.035 & 0.046 & 0.8323 & 0.032 & 1 & 0.65 & 0.9614 & -1.51 & 1 & 0.71 & 0.0495 \\
\hline$A B$ & -0.062 & 0.043 & 2.15 & 0.1634 & -3.71 & 1 & 0.80 & 0.0003 & -5.92 & 1 & 0.87 & $<0.0001$ \\
\hline$A C$ & -0.027 & 0.043 & 0.42 & 0.5287 & 3.25 & 1 & 0.80 & 0.0010 & -0.70 & 1 & 0.87 & 0.4340 \\
\hline$A D$ & $\underset{003}{-5.000 \mathrm{E}}$ & 0.043 & 0.014 & 0.9082 & -0.25 & 1 & 0.80 & 0.7625 & 2.39 & 1 & 0.87 & 0.0147 \\
\hline$B C$ & -0.076 & 0.043 & 3.20 & 0.0393 & 3.22 & 1 & 0.80 & 0.0011 & 0.032 & 1 & 0.87 & 0.9712 \\
\hline$B D$ & 0.026 & 0.043 & 0.38 & 0.5474 & -2.39 & 1 & 0.80 & 0.0090 & -1.56 & 1 & 0.87 & 0.0915 \\
\hline$C D$ & -0.024 & 0.043 & 0.31 & 0.5857 & 0.98 & 1 & 0.80 & 0.2380 & 3.42 & 1 & 0.87 & 0.0013 \\
\hline$A^{2}$ & 0.085 & 0.033 & 6.88 & 0.0192 & 3.59 & 1 & 0.61 & $<0.0001$ & -0.57 & 1 & 0.66 & 0.3992 \\
\hline$B^{2}$ & 0.038 & 0.033 & 1.36 & 0.2625 & 4.76 & 1 & 0.61 & $<0.0001$ & 0.92 & 1 & 0.66 & 0.1830 \\
\hline$C^{2}$ & 0.11 & 0.033 & 10.48 & 0.0055 & 1.83 & 1 & 0.61 & 0.0089 & 1.30 & 1 & 0.66 & 0.0676 \\
\hline$D^{2}$ & 0.019 & 0.033 & 0.35 & 0.5649 & 3.20 & 1 & 0.61 & $<0.0001$ & 2.42 & 1 & 0.66 & 0.0024 \\
\hline $\mathrm{R}^{2}$ & \multicolumn{4}{|c|}{0.8797} & \multicolumn{4}{|c|}{0.9488} & \multicolumn{4}{|c|}{0.9082} \\
\hline Adj. $R^{2}$ & \multicolumn{4}{|c|}{0.7675} & \multicolumn{4}{|c|}{0.9011} & \multicolumn{4}{|c|}{0.8226} \\
\hline Pred. $\mathrm{R}^{2}$ & \multicolumn{4}{|c|}{0.3072} & \multicolumn{4}{|c|}{0.7053} & \multicolumn{4}{|c|}{0.4714} \\
\hline CV (\%) & \multicolumn{4}{|c|}{31.10} & \multicolumn{4}{|c|}{5.32} & \multicolumn{4}{|c|}{5.63} \\
\hline AP & \multicolumn{4}{|c|}{11.394} & \multicolumn{4}{|c|}{14.782} & \multicolumn{4}{|c|}{12.512} \\
\hline
\end{tabular}

*CE: Coefficient of estimate, SE: Standard error, SN: Sieve number, MTT: Microwave treatment time, CM: Concentration of methanol, ST: Soaking time, CV: Coefficient of variation, $R^{2}$ : Regression coefficient, AP: Adequate precision

The optimum level of SN, MTT, CM and ST to achieve maximum values of TFC $(1.47 \mathrm{~g} / 100 \mathrm{~g} \mathrm{dw}), \mathrm{BCBC}$ $81.09(\%)$ and LARC $77.03(\%)$ were found to be 132.94, 110.668 and 139.995 meshes/inch, 1.85, 2.45 and 1.69 min, 99.87, 75.27 and $99.99 \%$ and $3.06,3.30$ and $5 \mathrm{~h}$, respectively.

The increase in TFC by decreasing the particle size may be attributed to the increase in the surface area and physical interaction between the flavonoids and the extracting solvent. The increase in TFC in response to an increase in microwave treatment time and solvent concentration may be correlated with the microwave-assisted release of bound flavonoids and amphiphilic nature of flavonoids present in N. nucifera seeds. However, an increase in the levels of MT'T and ST beyond the optimum limits suggested by the proposed model results in a decrease in TFC of the extracts which may be attributed to the possible oxidation and decomposition of the flavonoids. The increase in BCBC and LARC in response to an increase in SN, MTT and CM may also be attributed to the increase in the extraction of flavonoids and other phytochemical antioxidant compounds.

\section{CONCLUSION}

In conclusion, the extraction of flavonoids from $N$. nucifera SKF was significantly increased linearly in response to an increase in $\mathrm{SN}$ (decrease in particle size), MT'T and CM but up to a certain limit. The BCBC and LARC were also found to be increased in linear and quadratic fashion in response to an increase in the $\mathrm{SN}$, MT'T and CM. The LARC was also increased as a linear function of ST. Relatively smaller particle size, prolonged microwave treatment and high methanol concentration favored the extraction of flavonoids. The present study 

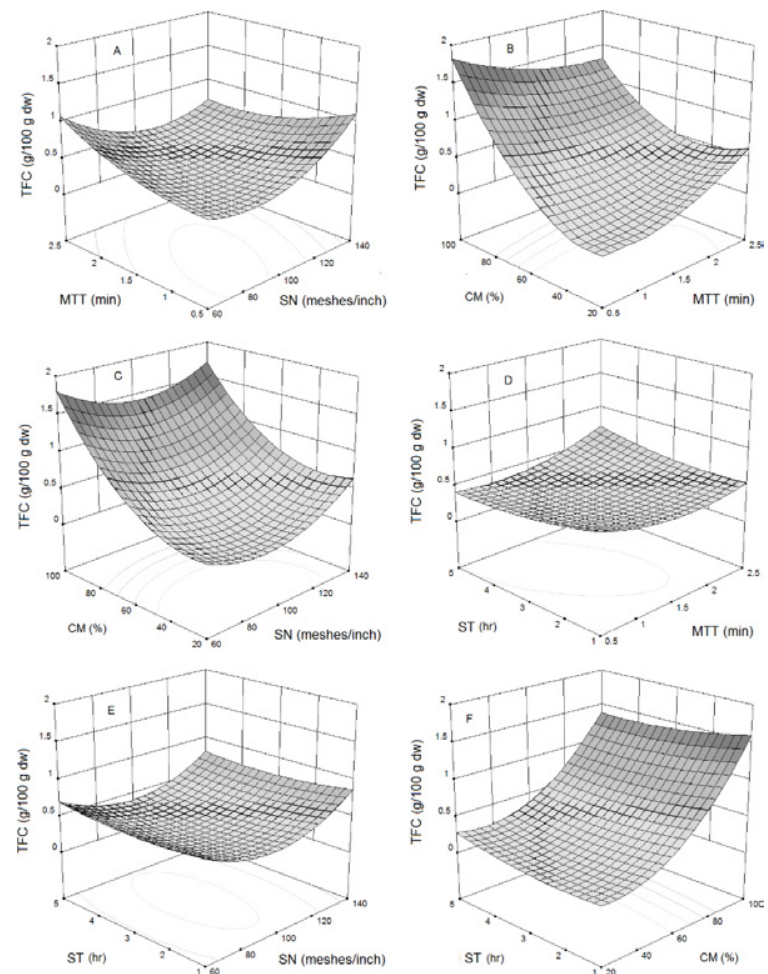

Figure 1: 3D response surface plots of the total flavonoid content of $\boldsymbol{N}$. nucifera seed kernel extracts obtained at various levels of selected extraction factors.

SN: Sieve number, MTT: Microwave treatment time, CM: Concentration of methanol, ST: Soaking time, TFC: Total flavonoid content.
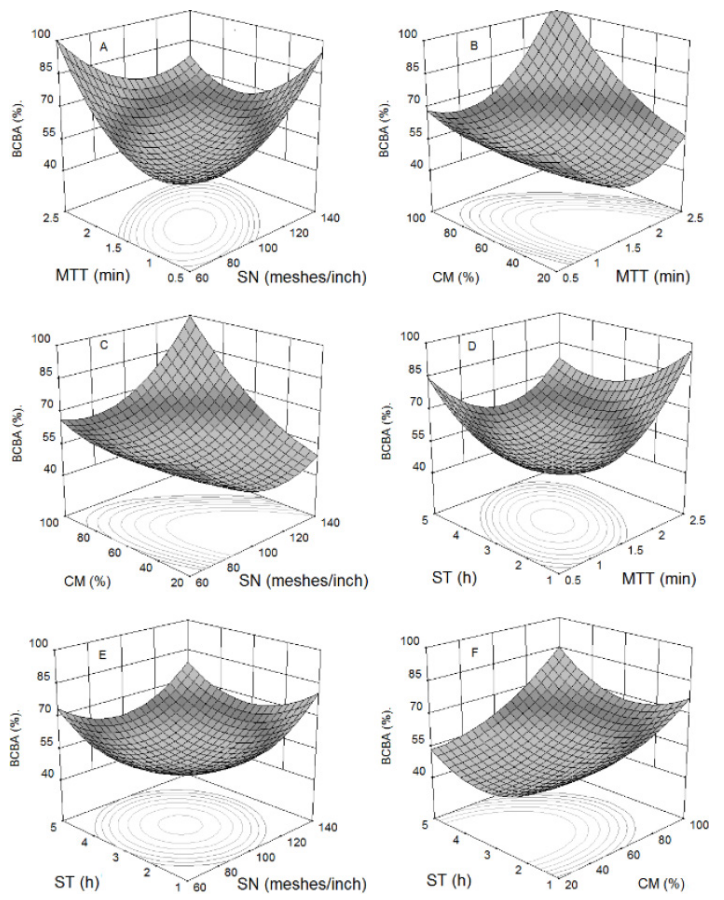

Figure 2: 3D response surface plots of the $\beta$-carotene bleaching capacity of $\boldsymbol{N}$. nucifera seed kernel extracts obtained at various levels of selected extraction factors.

SN: Sieve number, MTT: Microwave treatment time, CM: Concentration of methanol, ST: Soaking time, BCBA: $\beta$-carotene bleaching activity.SN: Sieve number, MTT: Microwave treatment time, CM: Concentration of methanol, ST: Soaking time, TFC: Total flavonoid content.
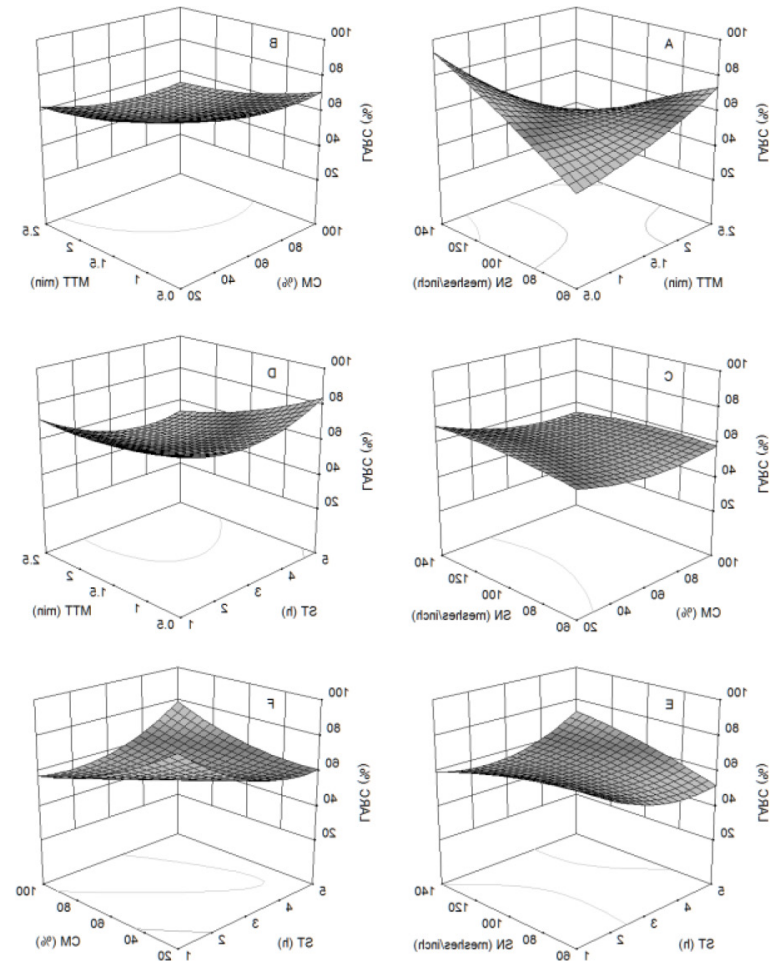

Figure 3: 3D response surface plots of the linoleic acid reduction capacity of $\boldsymbol{N}$. nucifera seed kernel extracts obtained at various levels of selected extraction factors.

$\mathrm{SN}$ : Sieve number, MTT: Microwave treatment time, CM: Concentration of methanol, ST: Soaking time, LARC: Linoleic acid reduction capacity.
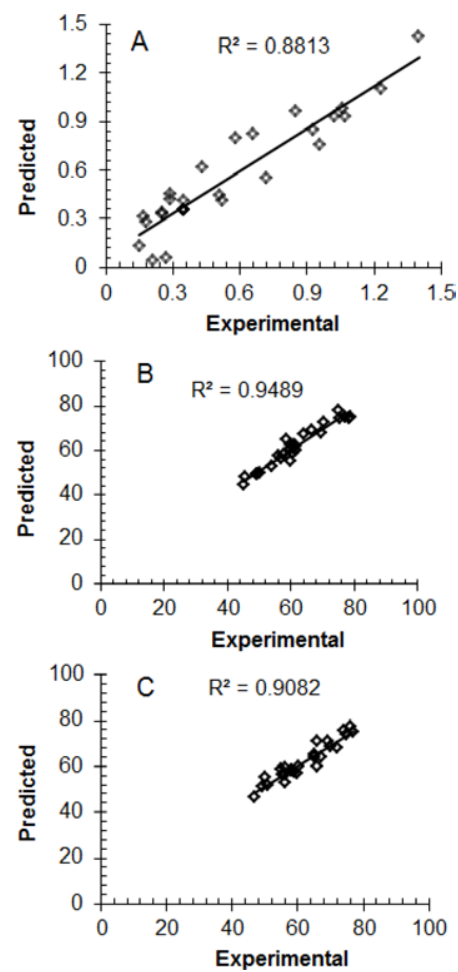

Figure 4: Correlation between the experimental and predicted values of $A$ : Total flavonoid content, $B$ : $\beta$-carotene bleaching activity and C: Linoleic acid reduction capacity of $N$. nucifera seed kernel extracts. 

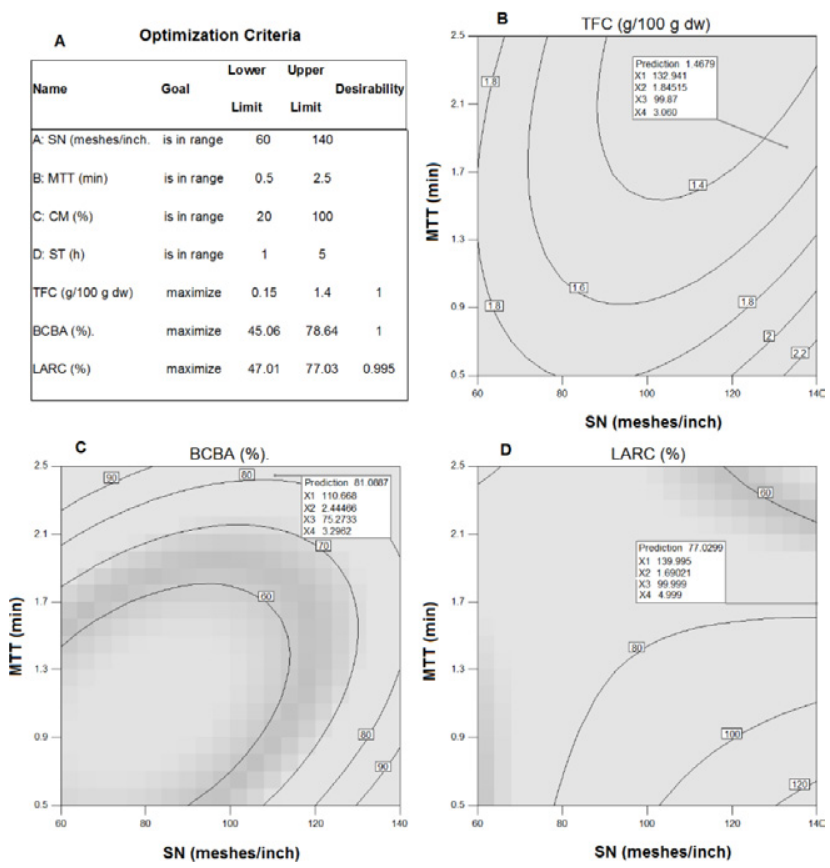

Figure 5: The criteria for optimization and the optimum levels of extraction factors to achieve the maximum value of the responses.

A: Optimization criteria, B: Total flavonoid content, C: $\beta$-carotene bleaching activity, $\mathbf{D}$ : Linoleic acid reduction capacity

Prediction: Optimum response, $\mathrm{X}_{1}$ : Sieve number, $\mathrm{X}_{2}$ : Microwave treatment time, $\mathrm{X}_{3}$ : Concentration of methanol, $\mathrm{X}_{4}$ : Soaking time

provides the optimum conditions for the extraction of flavonoids present in N. nuifera seeds. The data would be a valuable contribution to the literature based on the extraction of plant flavonoids and their antioxidant potential for medicinal and pharmaceutical applications.

\section{ACKNOWLEDGEMENT}

The authors are grateful to the Department of Biochemistry and Institute of Chemical Sciences, Bahauddin Zakariya University, Multan, Pakistan for providing the laboratory facilities throughout the experimental work.

\section{CONFLICT OF INTEREST}

The authors declare that there are no conflicts of interest.

\section{ABBREVIATIONS}

AP: Adequate precision; BCBC: $\beta$-carotene bleaching capacity; CCD: Central composite design; CE: Coefficient of estimate; CM: Concentration of methanol; CV: Coefficient of variation; LARC: Linoleic acid reduction capacity; MTT: Microwave treatment; $\boldsymbol{R}^{2}$ : Regression coefficient; SE: Standard error; SKF: Seed kernel flour; SN: Sieve number, time, ST: Soaking time; TFC: Total flavonoid content.

\section{REFERENCES}

1. Dai J, Mumper RJ. Plant Phenolics: Extraction, Analysis and Their Antioxidant and Anticancer Properties. Molecules. 2010;15(10):7313-52.

2. Karami Z, Emam-Djomeh Z, Mirzaee HA, Khomeiri M, Mahoonak AS, Aydani E. Optimization of microwave assisted extraction (MAE) and soxhlet extraction of phenolic compound from licorice root. J Food Sci Technol. 2015;52(6):3242-53.

3. Khoddami A, Wilkes M, Roberts T. Techniques for Analysis of Plant Phenolic Compounds. Molecules. 2013;18(3):2328-75.

4. Silva EM, Rogez H, Larondelle Y. Optimization of extraction of phenolics from Inga edulis leaves using response surface methodology. Sep Purif Technol. 2007;55(3):381-7.

5. Zhang $\mathrm{Y}$, Zheng B, Tian Y, Huang S. Microwave-assisted extraction and anti-oxidation activity of polyphenols from lotus (Nelumbo nucifera Gaertn.) seeds. Food Sci Biotechnol. 2012;21(6):1577-84.

6. Zhu J, Fu Q. Optimization of ultrasound-assisted extraction process of perilla seed meal proteins. Food Sci Biotechnol. 2012;21(6):1701-6.

7. Ranic M, Nikolic M, Pavlovic M, Buntic A, Siler-Marinkovic S, DimitrijevicBrankovic S. Optimization of microwave-assisted extraction of natural antioxidants from spent espresso coffee grounds by response surface methodology. J Clean Prod. 2014;80:69-79.

8. Veggi PC, Martinez J, Meireles MAA. Fundamentals of Microwave Extraction. Microwave-assisted Extraction for Bioactive Compounds. Boston, MA: Springer US. 2012;15-52. [cited 2016 Mar 4]. Available from: http://link. springer.com/10.1007/978-1-4614-4830-3_2

9. Usher G. Iron chelating activity, phenol and flavonoid content of some medicinaln plants from Iran. Constable and Company Ltd. 1974.

10. Zhishen J, Mengcheng T, Jianming W. The determination of flavonoid contents in mulberry and their scavenging effects on superoxide radicals. Food Chem. 1999;64(4):555-9.

11. Cook NC, Samman S. Flavonoids-chemistry, metabolism, cardioprotective effects and dietary sources. J Nutr Biochem. 1996;7(2):66-76.

12. Augusto TR, Salinas ESS, Alencar SM, D'arce MABR, DeCamargo AC, DeVieira TMFS. Phenolic compounds and antioxidant activity of hydroalcoholic extracts of wild and cultivated murtilla (Ugni molinae Turcz.). Food Sci Technol Camp. 2014;34(4):667-79.

13. Garcia-Salas P, Morales-Soto A, Segura-Carretero A, Fernández-Gutiérrez A. Phenolic-Compound-Extraction Systems for Fruit and Vegetable Samples. Molecules. 2010;15(12):8813-26.

14. Parimala M, Shoba FG. Phytochemical analysis and in vitro antioxidant acitivity of hydroalcoholic seed extract of Nymphaea nouchali Burm. f. Asian Pac J Trop Biomed. 2013;3(11):887-95.

15. Kim MJ, Shin HS. Antioxidative effect of lotus seed and seedpod extracts. Food Sci Biotechnol. 2012;21(6):1761-6.

16. Kim T, Kim HJ, Cho SK, Kang WY, Baek H, Jeon HY, et al. Nelumbo nucifera extracts as whitening and anti-wrinkle cosmetic agent. Korean $\mathrm{J}$ Chem Eng. 2010;28(2):424-7.

17. Nawaz H, Shad MA, Abbasi ST. Extraction Optimization of Phenolic Antioxidants from microwave treated Nelumbo nucifera Seed Flour. Free Radic Antioxid. 2017;7(1):63.

18. Paudel KR, Panth N. Phytochemical Profile and Biological Activity of Nelumbo nucifera. Evid Based Complement Alternat Med. 2015;2015:1-16.

19. Shad MA, Nawaz H, Siddique F, Zahra J, Mushtaq A. Nutritional and functional characterization of seed kernel of lotus (Nelumbo nucifera): Application of response surface methodology. Food Sci Technol Res. 2013;19(2):163-72.

20. Wu MJ, Wang L, Weng CY, Yen JH. Antioxidant Activity of Methanol Extract of the Lotus Leaf (Nelumbo nucifera Gertn.). Am J Chin Med. 2003;31(05):687-98

21. You JS, Lee YJ, Kim KS, Kim SH, Chang KJ. Anti-obesity and hypolipidaemic effects of Nelumbo nucifera seed ethanol extract in human pre-adipocytes and rats fed a high-fat diet. J Sci Food Agric. 2014 Feb;94(3):568-75. 
Zhang Y, Lu X, Zeng S, Huang X, Guo Z, Zheng Y, et al. Nutritional composition, physiological functions and processing of lotus (Nelumbo nucifera Gaertn.) seeds: A review. Phytochem Rev. 2015;14(3):321-34.

23. Nawaz H, Shad MA, Muntaha ST, Muzaffar S. Phytochemical Composition and Antioxidant Potential of Oven Heated and Microwave Treated Ginger (Zingiber officinale Roscoe). Free Radic Antioxid. 2018;8(2).
24. Shon MY, Kim TH, Sung NJ. Antioxidants and free radical scavenging activity of Phellinus baumii (Phellinus of Hymenochaetaceae) extracts. Food Chem. 2003;82(4):593-7.

25. Nawaz H, Shad MA, Rehman T, Ramzan A. Influence of high-dose gamma radiation and particle size on antioxidant properties of Maize (Zea mays L.) flour. Braz J Pharm Sci. 2016;52(4):771-80.

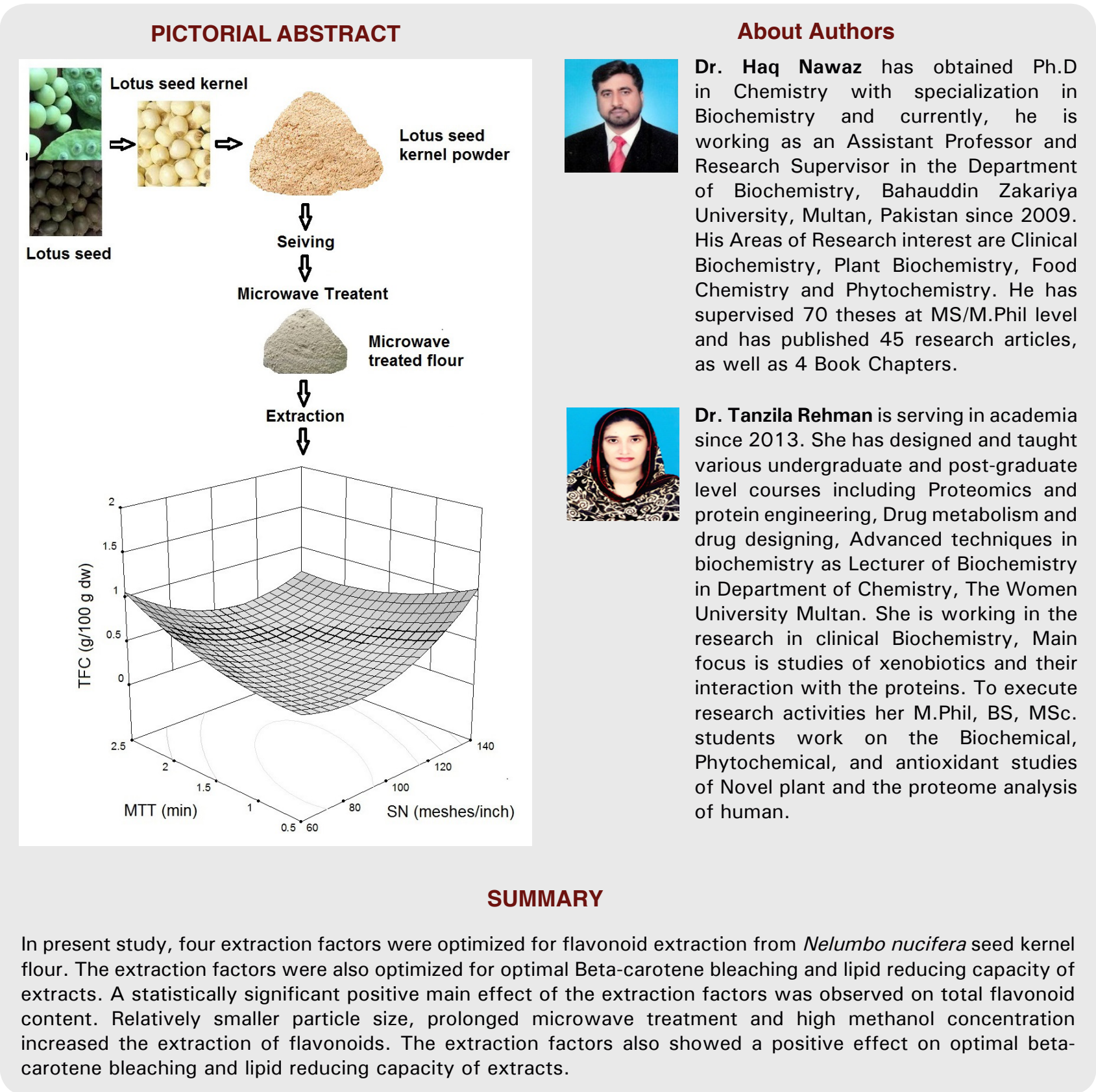

Cite this article: Nawaz $H$, Shad MA, Shah $M$, et al. Response Surface Optimization of Flavonoids Extraction, Beta Carotene Bleaching and Lipid-reducing Capacity of Nelumbo nucifera Seed Kernel Extracts. Indian J of Pharmaceutical Education and Research. 2021;55(1s):s193-s201. 